\title{
Mathematical e-learning: state of the art and experiences at the Open University of Catalonia
}

\author{
A. Juan*, A. Huertas, C. Steegmann, C. Corcoles and C. Serrat \\ Department of Computer Sciences, Open University of Catalonia, \\ Rambla del Poblenou, 156, 08018 Barcelona, Spain
}

(Received 23 May 2007)

\begin{abstract}
In this article we present a review of the state of the art in mathematical e-learning and some personal experiences on this area developed during the last eleven years at the Open University of Catalonia (UOC), a completely online university located in Spain. The article discusses important aspects related to online mathematics courses offered in higher education programs, including: benefits and challenges, universities offering this type of education, methodological considerations, emergent technologies, learning projects and environments, etc. Also, key aspects of the UOC mathematical e-learning model and its historical evolution are described and analysed. Special attention is paid to mathematical curricula in computer sciences degrees, where a lot of work needs to be done in order to adapt mathematics courses to the continuously changing educational necessities of students. A curricula design proposal, based on a top-down approach, is presented as a best practice. Finally, some trends and future perspectives on the subject are suggested.
\end{abstract}

Keywords: mathematical education; e-learning; higher education

\section{Introduction}

Information and communication technologies have produced important changes in modern societies. These changes, in turn, have a strong influence on the university environment since they imply the appearance of both new educational necessities and new methodological opportunities [1]. As a result of this influence, innovative learning models arise in which the role that instructors and students develop differs partly from the one established during the last century. This way, in the Internet-based education or e-learning, a redefinition of the teaching-learning process is taking place. This redefinition affects both universities - as institutions - and the knowledge areas they cover.

One important point regarding new educational necessities is that, in the information society, our individual knowledge must be reviewed and updated throughout our entire life. In effect, a university degree is not enough to provide us with all those concepts and skills that we will need in our extensive and changing professional career but, on the contrary, a university degree constitutes just the starting point of a continuous educational process which will last all our life. Therefore, a significant part of this educational process must be compatible with individual work responsibilities or familiar duties, and

*Corresponding author. Email: ajuanp@gmail.com 
information and communication technologies can be of great help in order to facilitate this compatibility.

In the methodological arena, educational technologies offer new ways to communicate, collaborate and participate in learning processes. These educational technologies include online environments for individual and collaborative learning, Internet resources for teaching and learning, academic materials in electronic format - which makes them more portable and allows for easy upgrades -, specific subject software, online communities, etc.

Since technology is changing the methods by which education is delivered, face-to-face colleges and universities across the world are confronting several transformations which affect the nature of the courses and degree programs they offer. These technological innovations have also driven the growth of distance learning opportunities, as students who are time bound - due to job or travel difficulties - or place bound - due to geographic location or physical disabilities- can now access courses and degree programs at their convenience. Because of the rapid growth of distance and global education, e-learning models are currently practiced widely all over the world. As Seufert, Lechner and Stanoevska [2] point out, "e-learning models can provide high-quality educational offerings at the same time they allow for convenient and flexible learning environments without space, distance or time restrictions'

Moreover, educational technologies facilitate the shifting from a traditional educational paradigm - centred on the figure of a masterful instructor - to an emergent educational paradigm which considers students as active and central actors in their learning process. In this new paradigm students learn technology and other students, what they
future academic or professional activitics.
one related to a knowledge transmission age
designs the course, guides and supervises $t$ is commonly known as 'teaching to learn'
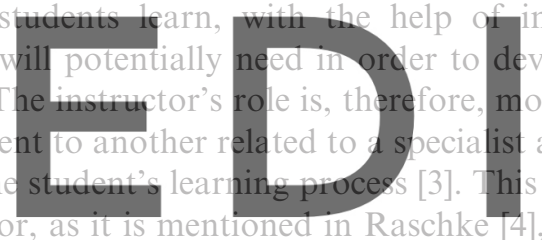
instructoro,
velop thein
oving from
agen who
s paradigm
7, the post-

modern university paradigm. Frontiers between both paradigms are not very clear since Register forfree at https/thwW. Scipediacom to downlead the version without the watermark

technologies - online courses, virtual classrooms and student support through e-mail or posted notes - are used in combination with traditional methodologies and curricula. On the other hand, it is frequent to find out online courses that combine a student-centred methodology with materials that come from the traditional model - lecture notes and blackboard dissertations, for example.

Regarding the area of mathematics ${ }^{1}$ teaching and learning, reforms are widespread not only in the e-learning arena but also in the traditional face-to-face education -, and many instructors have been encouraged to try new strategies such as online support, collaborative learning, integration of mathematical software in their courses, and new, engaging curriculum that requires promoting conceptual understanding by the students instead of procedural knowledge [5]. According to Lai, Pratt and Grant [6], with respect to the state of the art in mathematical e-learning (MEL), there are many aspects to consider, among others: (a) the type, range and amount of technology being used, (b) the range and level of courses and programs provided, (c) the pedagogical issues - i.e. how the technology is being used and (d) the institutional support provided both for students and instructors.

In the case of an entire online university like the Open University of Catalonia, which uses an asynchronous learning model, the student-centred educational paradigm impregnates all academic acts and activities. As part of a wider academic catalogue, the UOC offers undergraduate and graduate degrees on Computer Sciences and Business 
Management since 1996, and it currently has more than 34,000 enrolled students and more than 400 instructors (tutors and lecturers). Technical and administration staff, students and instructors share information and knowledge via the Virtual Campus (www.uoc.edu), an extranet specially designed for developing and managing online university degrees.

\section{Benefits of mathematical e-learning}

E-learning programs and technologies can offer relevant benefits to students. According to Zirkle [7], the following are some of the main benefits for them:

- Relief from the constraints imposed by having to attend a class on campus at a scheduled time.

- Possibility of self-pacing some of the course content and activities.

- Improvement in access to education for those students with physical disabilities.

- Contribution to the development of technical skills.

Regarding the last of the benefits mentioned above, it seems clear that the student's technical skills and competencies may be significantly improved by having to: (a) interact with mathematical software, (b) communicate with instructors and other students via e-mail, posted notes or chats and (c) develop collaborative projects via web-based

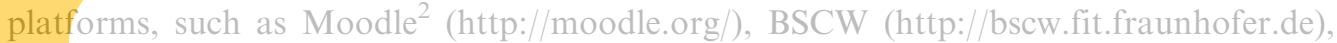
etc. Of course, these social and technical experiences can be very valuable for the student's

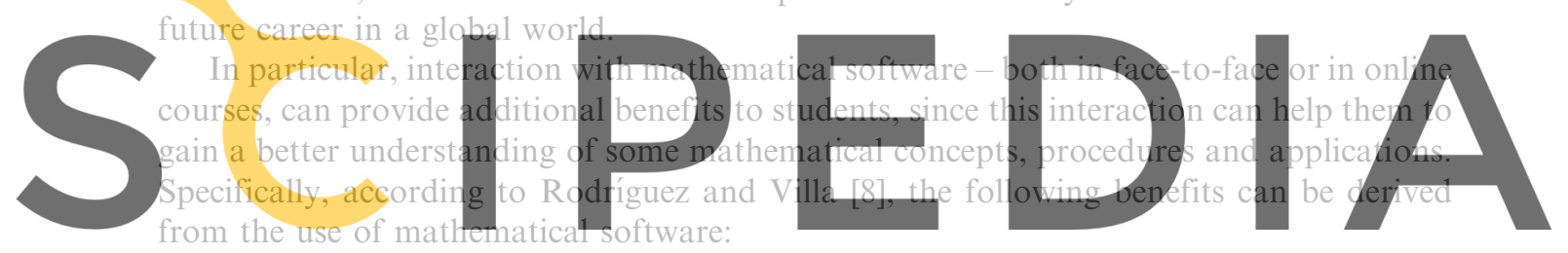

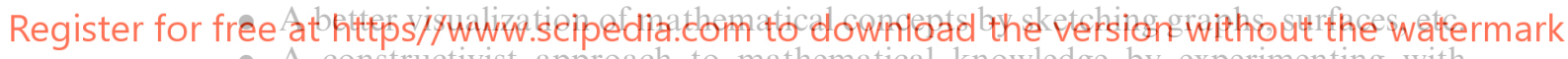

- A constructivist approach to mathematical knowledge by experimenting with different scenarios and performing 'what-if analysis' (parametric analysis) or sensitive analysis.

- A development of a critical spirit by facilitating different solving methods analytical, simulation, etc. - to problems and more complete analysis of the results.

- A release from mechanical work: once the student has assimilated the concepts and the solving process for simple cases, she can - and should - use computers to solve more difficult calculations, just as she will do in her future career. In this sense, computers allow to save time that traditionally has been employed in solving operations manually. This time, in turn, can be employed in more constructive processes, such as learning more mathematical concepts or exploring additional applications of the already learned ones.

- A reduction in the gap between theory and practice: the use of mathematical software allows the modelling and solving of real problems, when real conditions and data can be used without having to add simplifying restrictions.

After more than ten years teaching online mathematics courses at the UOC, we can state that integration of software-based practices in these courses increases students' motivation during the learning process, which eventually influences their performance in a positive way. 
Finally, an additional benefit for e-learning students might be the possibility of interacting with world-class specialists that collaborate online with the institution, or even the possibility of completing some degree courses at universities from other regions or countries.

Internet-based distance education programs, in combination with the use of mathematical software, also offer several benefits to instructors and institutions:

- The opportunity to develop networked teams of instructors, who can collaborate online both in educational and research programs.

- The possibility of offering education in several languages to students from different countries or regions. This, in turn, could help foreign-language students enrolled in mathematics courses to avoid potential problems such as those detected by Barton, Chan, King, Neville-Barton \& Sneddon [9].

- The opportunity to revisit and improve curricula, teaching methodologies and materials - e.g. laboratory tutorials could be employed without typical restrictions on availability of computer rooms; furthermore, use of multimedia and interactive documents is enhanced.

- The possibility to model and solve real life problems that are either too complicated or too time consuming to be analysed within a limited time or without the assistance of computers.

- In the context of the European Space for Higher Education (www.bologna-bergen 2005.no), the opportunity of sharing materials, methodologies
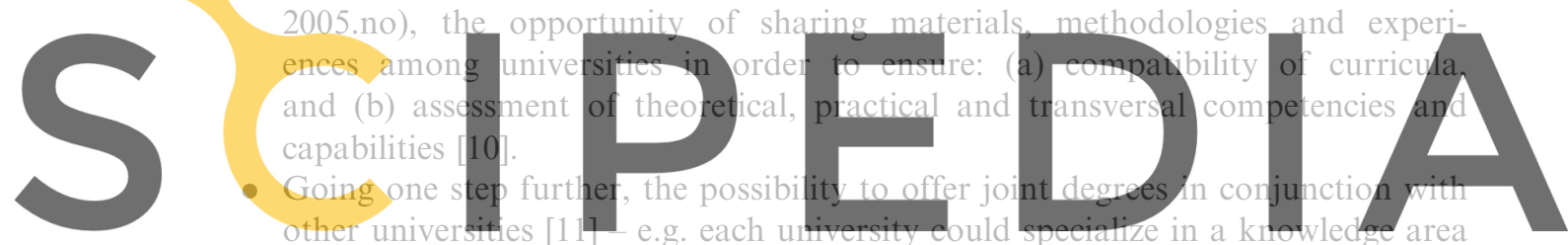

and offer the corresponding part of the degree; different approaches on the use

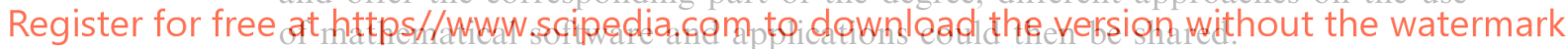

\section{Students' and instructors' perceptions of e-learning}

Until now, we have seen very few scientific articles and reports about the students' opinions of Internet-based education. Sikora and Carroll [12] found post-secondary students taking courses both on campus and at distance to be equally satisfied with distance courses and classroom courses. Additional studies have documented the favourable perceptions of students involved in distance education [13]. With regard to student performance in distance education, Willis and Joyner [14] found no differences between on-campus students who took an information technology class online, and off-campus students who also took the class online. In their European survey report, McCullough and Aimard [15] found out that $92 \%$ of the surveyed population - students and instructors considered that e-learning had really supported their teaching/study, mainly because of the advantages it offers in flexibility, better time management and autonomy/responsibility. Surveyed students and instructors considered required self-discipline as the main obstacle to teaching/studying in an e-learning environment. On the other hand, involvement intensity of the participants and presence and quality of technical support were considered as the key success factors in e-learning education. Finally, $95 \%$ of the surveyed population associated e-learning with innovation, in the sense that it creates new kinds of relationships 
between the different agents involved in the learning/teaching process and gives wider access to content and knowledge.

\section{Challenges of mathematical e-learning}

Typically, any type of distance education presents higher dropout rates than traditional programmes [16]. The nature of distance education can create a sense of isolation in learners, and students can feel disconnected from the instructor, the rest of the class and even the institution. It is necessary, then, that instructors provide just-in-time guidance to student's activities and also that they provide regular - almost daily - feed-back on these activities, i.e.: not only scores, but also detailed revisions or, at least, models of the correct solutions. On the other hand, communication among students should also be facilitated and promoted by instructors - who should encourage students' participation in the web spaces devoted to that function -, and by the institution - which should provide an easily usable and efficient web platform that could be used as an online virtual campus. As Simonson, Smaldino, Albright and Zvacek [17] point out, another usual problem is students having difficulties with the use of technology. Both instructors and their institutions should ensure that students are prepared and have the necessary training before starting an e-learning course or program.

In the case of mathematical e-learning, some additional barriers might arise, since this

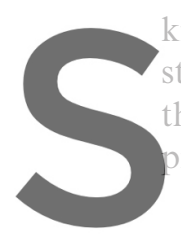
knowledge area tend

students are required to

thinking skills. In this

roblems:

- Students'
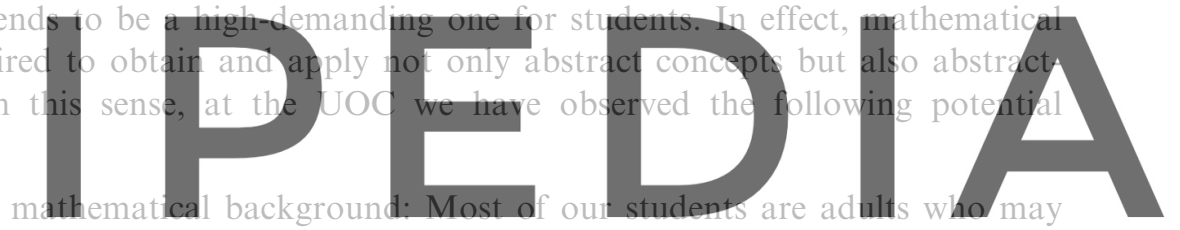

have not been in contact with mathematics and mathematical notation for years.

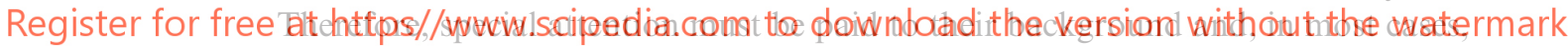

some reinforcement or reviewer courses must be given to them before starting with the more advanced ones.

- Students' lack of motivation: Most students from Computer Sciences, Business Management and Social Sciences degrees show a lack of motivation for mathematical subjects. This lack of motivation is mainly due to the fact that, in many situations, they do not understand the added value that these courses - specially the most theoretical ones - offer to their curriculum. This is a risk factor since, as Meyer [18] points out, online students need motivation as a very important variable to learn in an online environment. Use of software-based activities and use of a professionally oriented approach can enhance students' motivation for these subjects. Recent research seems to support the convenience of using this professionally oriented approach. For instance, [19] conclude that: 'An important dimension of curricula that can encourage students towards broader conceptions of mathematics is making explicit connections between students' courses and the world of professional work'.

- Overloaded courses: Often, the number of hours that students have to invest to pass mathematics-related courses is greater than the number of hours invested in passing other courses with equivalent number of credits. This is especially true in the case of students with a poor mathematical background - which, as we said, is not an infrequent situation among adult students. Therefore, it becomes 
sometimes necessary to review and readjust the course workload to the real number of credits that it has been assigned.

- Lack of face-to-face interaction: Many learning activities, especially those that provide practical skills, benefit from the face-to-face interaction among instructors and students. Obviously, in an online environment this kind of interaction is not possible and, therefore, other interaction methodologies - e.g. collaborative learning or online forums - must be introduced in order to compensate this deficiency. Some studies have already shown the effectiveness of collaborative learning in the mathematical education arena [20].

- Poor integration of mathematical notation with computers: Even when there are several software solutions that offer equations-editing capabilities, and even when a lot of work is still being developed in this area, it is still far more tedious to communicate mathematical concepts by using mathematical notation in a digital environment than by using it in a more traditional environment like a blackboard, a simple sheet, etc. Students should use plain text whenever possible to avoid having to invest more time than necessary in equations edition.

(Table 1) summarizes the main students' challenges and problems detected by the UOC faculty over the last years and the methodological measures proposed to reduce their effects:

On the instructor side, one important challenge can be the time required to design the course and, once it has started, to effectively provide guidance and support to students [21] Teaching with technology presents continual deman professional developinent and, therefore, universities mus specific refresher courses and efficient technological tools and development of online courses, inclu measures can significantly contribute to

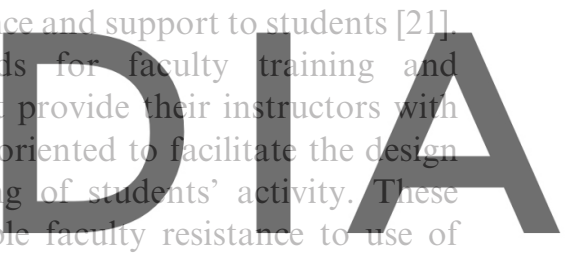

e-learning technologies [22] [23] or mathematical software [24].

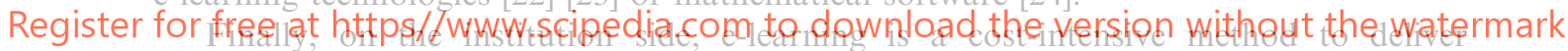

education. The start-up and ongoing costs of e-learning courses and programs are significant, due in part to the cost of: (a) communication technology - dedicated servers,

Table 1. MEL students' challenges and corresponding methodological measures at the UOC.

Challenge/Problem

1. Perception of isolation

2. Lack of technological skills

3. Poor mathematical background

4. Lack of motivation

5. Overloaded courses

6. Lack of face-to-face interaction

7. Limited equations-editing capabilities
Proposed solution

- Instructors should provide just-in-time guidance

- Instructors should provide daily feed-back

- Instructors should enhance use of forums

- Institutions should offer preparatory courses

- Institutions should enhance usability of e-learning environment

- Institutions should offer reinforcement courses and materials

- Instructors should use a professional-oriented approach

- Instructors should integrate mathematical software in courses

- Faculty should review and readjust course workload

- Instructors should promote collaborative learning and use of forums

- Students should use plain text whenever possible 
telecommunication lines, etc. - and specialized staff who must support it, (b) licensed software - web platforms, operating systems, database managers, mathematical software, utilities, etc. - and (c) formative courses and programs for faculty and administration staff, both at methodological and technical levels, including annual upgrading courses on new versions of mathematical software and web platforms.

\section{Universities offering mathematical e-learning}

Colleges and universities involved with career and technical education have been developing courses and programs for delivery through Internet-based distance education. Curricular models vary, and schools range from offering a handful of courses to full degree options. Some universities are providing the same courses to distance and on-campus students. These universities are called dual-mode or mixed-mode institutions [25]. On physical campuses, students' traditional face-to-face learning is often augmented by the use of web-based materials and support and multimedia presentations. In this sense, it seams clear that face-to-face and e-learning models are converging in traditional institutions. Just to give some numbers: According to the Sloan Consortium [26], in the US, almost two-thirds of all schools offering face-to-face courses also offer online courses, and more than 40\% of schools offering Master's degree programs also offer these programs online. There, the total amount of e-learning students is estimated to be about 2.5 million, with an estimated increasing rate of $18 \%$ each year.
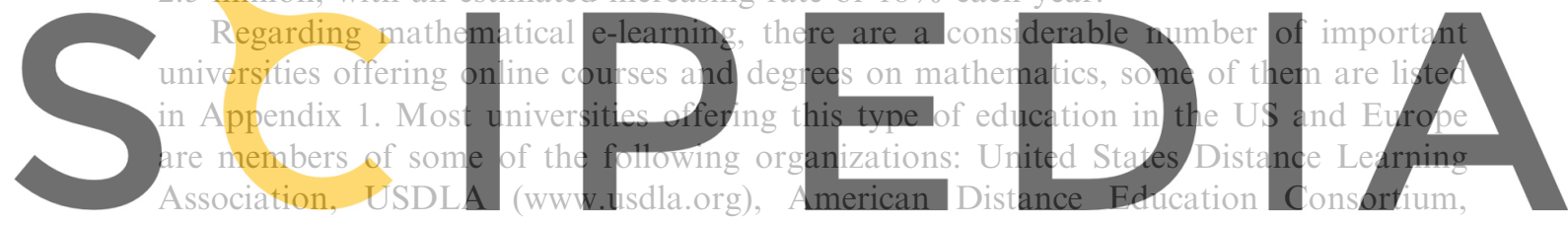

ADEC (www.adec.edu), European Association of Distance Teaching Universities,

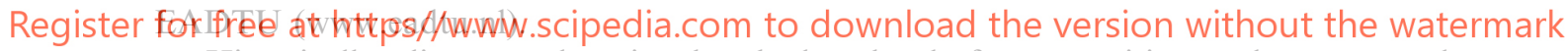

Historically, distance education has had to battle for recognition and consequently procedures for demonstrating quality were developed early. Credibility of quality management has increased with the introduction of e-learning. Some two well-known examples of international organizations involved in e-learning quality accreditation are: the European Foundation for Quality in e-Learning or EFQUEL (www.quality foundation.org), and the International Organization for Standardization (ISO) - Standard on Quality for e-Learning (www.iso.org).

\section{Some methodological aspects regarding mathematical e-learning}

Current research recognizes the importance of all forms of learning being focused on the students, with them being active participants in their learning, where they can make choices in how learning is delivered [6]. Following these tendencies, universities are increasingly using a student-centred approach to their teaching - both in face-to-face and in distance education. Instructors are taking advantage of the opportunities offered by the technology to implement an innovative approach where students are at the centre of the class and instructors are acting as guides or facilitators [27]. Interaction is seen as important, with instructors using technology to increase interaction between students and themselves and also among students - collaborative learning. Despite this predominant tendency, some studies point out an infrequent use of learner-centred instruction 


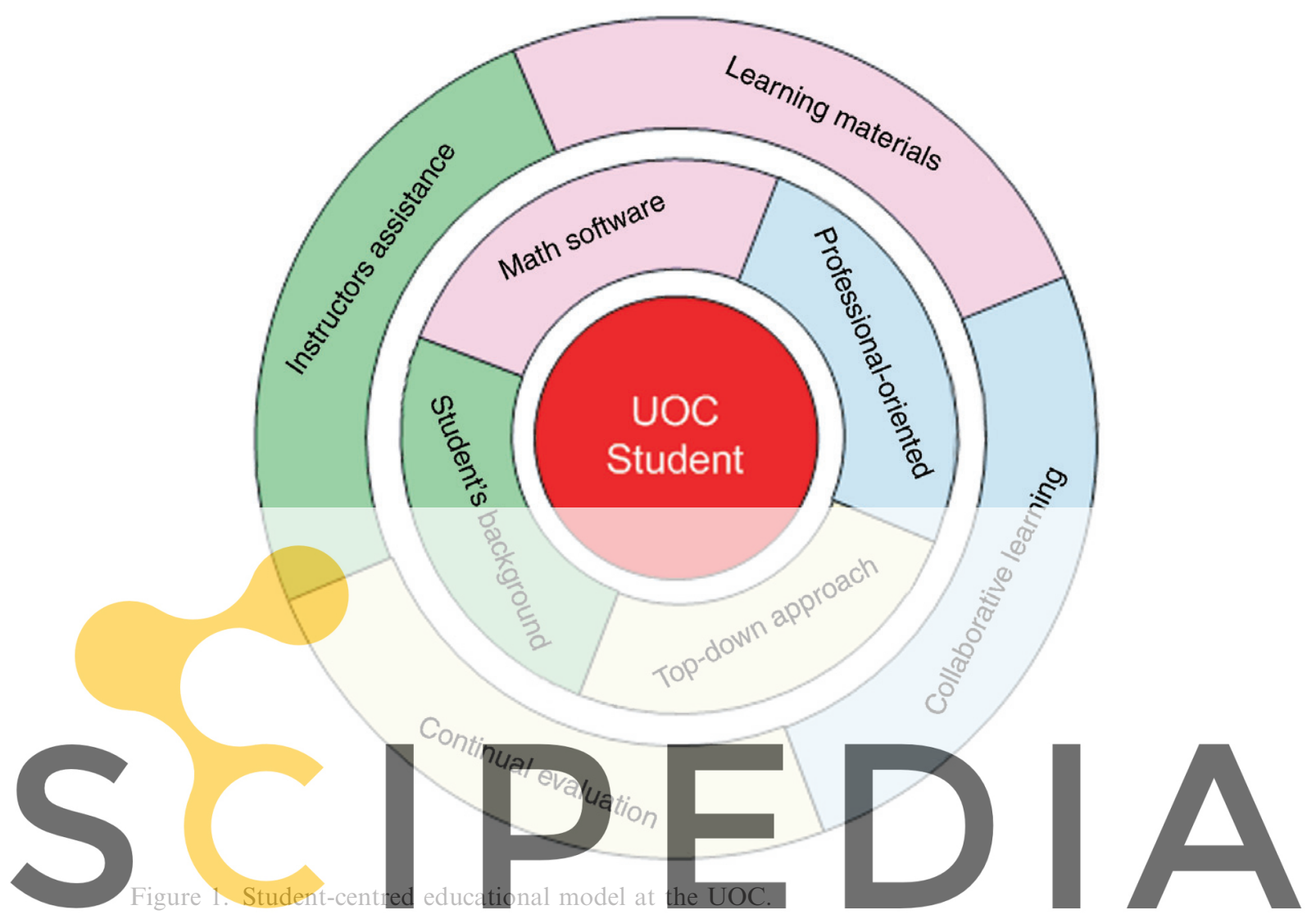

Register for free at https / www scipedia.com to downlond the version without the watermark have been also identified [29]. In the case of the UOC pedagogical model, the student is considered to be the main agent of the learning process, which relies on four fundamental pillars: (a) specifically designed learning materials, (b) instructors' assistance, (c) continual evaluation process, and (d) online collaborative learning. (Figure 1) shows a graphical representation of our model. The external annulus corresponds to the general e-learning model, which applies to all courses at the UOC. The internal annulus corresponds to specific courses on mathematics. Some important aspects of this model will be explained and discussed throughout the remainder of this article.

Based on our experiences at the UOC, we can state that learning mathematics at a distance using technology without face-to-face instructional support is not easy at all. As mentioned before, the majority of our students are working adults, most of them between 25 and 35 years old. In most cases, these students left mathematical education several years ago and, therefore, they tend to suffer from a lack of basic mathematical background which, additionally, causes them some anxiety. These problems need to be addressed before starting the regular courses. Furthermore, specific courses should be necessary to prepare students for the actual technological and pedagogical characteristics of the e-learning environment that they will use when completing a degree.

During the course development, instructors should make use of different available e-learning methods and strategies - such as dynamic presentations, laboratory tutorials, simulations, concept discussions, interaction and collaboration with other 
students - to support activity, exploration and creation, which could assist students in constructing their own mathematical knowledge; students should learn mathematics with understanding, actively building new knowledge from experience and prior knowledge. Additionally, feedback from instructors and constant consultation by e-mail or posted notes are fundamental components of an efficient e-learning process. Effective mathematics teaching requires understanding what students know and need to learn and then challenging and supporting them to learn it well. As Sakshaug [30] points out, 'Mathematics educators need to establish relationships between learners and themselves and among learners in distance education settings.'

Another important issue to address refers to the efficiency of the evaluation process. In this sense, it is critical to define evaluation strategies that allow ensuring authorship of all online tests carried out during the semester. At the same time, final face-to-face exams might be necessary to complement the evaluation process [31]. These exams should always be coherent - in contents and difficulty levels - with already performed tests [32].

Finally, it should be noted that a mathematical e-learning curriculum is more than a collection of activities: it must be coherent, focused on important mathematics, and it must efficiently integrate the use of mathematical software and Internet resources.

\section{Technologies and projects related to mathematical education}

A wide range of technology is used at universities offering mathematical e-learning:

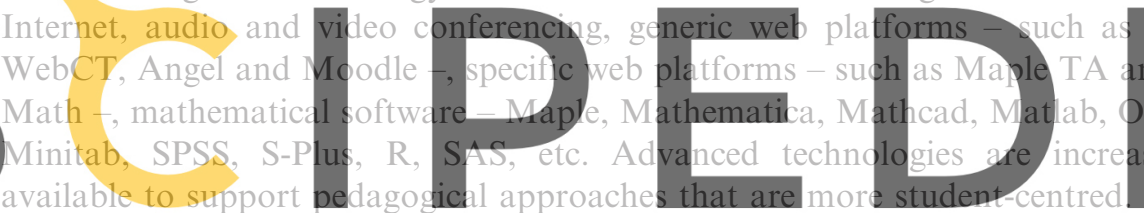

Furthermore, as Lee [33] states, technology fits well with constructivism through
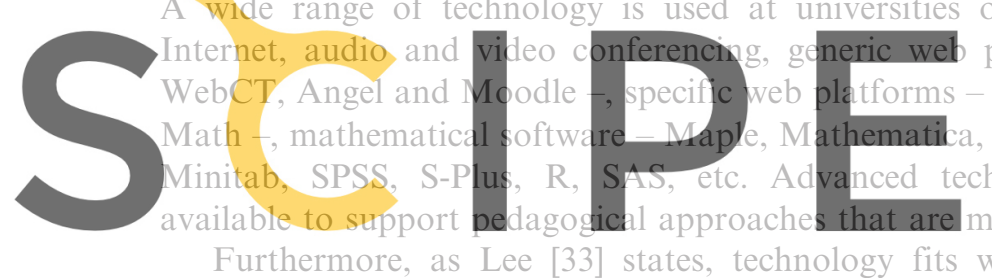

hypertext, which are types of multimedia elements that make sense in the constructivist paradigm.

Finally, it is important to note that various technologies and e-learning platforms are now available for using dynamic mathematical notation on the web and for viewing both mathematically rich material and graphs. Most of these technologies are based on two eXtensible Markup Language (XML) standards: Mathematical Markup Language (MathML) and Scalable Vector Graphics (SVG) [34] [35]. Many institutions also use Java applets for developing interactive web pages and course materials. Appendix 2 contains a list of relevant technological projects related to mathematical e-learning. Additionally, a list of advanced technologies and standards that are modelling the present and future of mathematical e-learning can be found in Appendix 3.

\section{Historical evolution of mathematical e-learning at the UOC}

In this section we will discuss some experiences regarding methodological evolution of mathematical e-learning at the UOC. In particular, we will focus on how mathematical e-learning has been evolving at the Studies of Computer Sciences (CS) during the last years. These Studies have been offered at the UOC since 1996. At the beginning, they had only a dozen of registered students. Nowadays, they have more than 3000 registered students. Each term more than 1000 students follow an introductory course on Logic, 


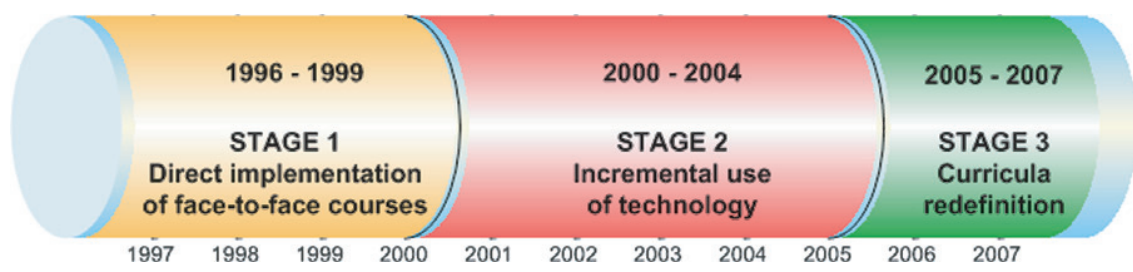

Figure 2. Historical evolution of MEL at the UOC.

more than 500 students follow an introductory course on Linear Algebra, more than 400 students follow courses on Calculus, Probability and Statistics, and more than 500 students follow a course on Discrete Mathematics. During all these years, there has been a continuous reforming process involving the way mathematics are taught and learned at the UOC. We can distinguish three major stages in this process (Figure 2).

\subsection{Stage 1 (1996 - 1999): direct implementation from face-to-face courses}

When the CS degree started in 1996, both the curricula and the methodological model of the traditional face-to-face universities were directly implemented in the new online

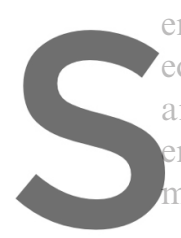
environment. For instan education with some all and, at best, some

environment was quite methodologieal approa
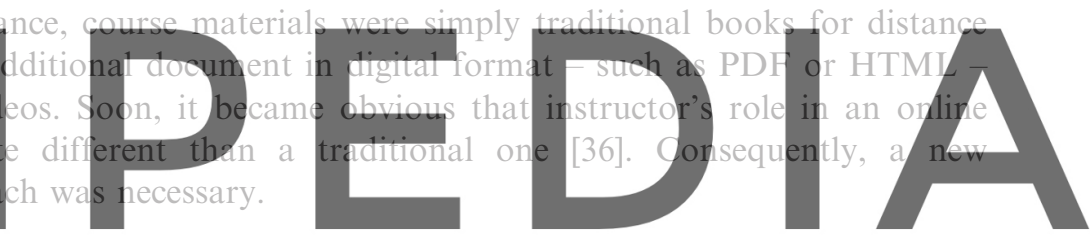

Register for free at https//www.scipedia.com to download the version without the watermark 8.2. Stage 2 (2000-2004): incremental use of technology and innovative methodologies

At this second stage, many innovative experiences were began. The goal was to improve the overall quality of learning-processes at the UOC. To pursue that goal, more information and communication technology resources were employed in the development of new mathematical materials and courses. Complementary materials, which reinforced practical applications of theoretical concepts, were developed and published online. Also, some projects regarding the development of open online materials were developed. The e-Math project (www.uoc.edu/in3/e-math) was born to promote the efficient use and integration of the education technologies - Internet and specialized software - as a fundamental part of most mathematical courses at the UOC, including: Algebra, Calculus, Probability and Statistics, Discrete Mathematics, etc. New learning materials, divided into individual modules named math-blocks, were developed and published online, usually in PDF or HTML format. These materials were designed as additional learning resources, and they were especially oriented to students with a poor mathematical background or to students looking for complementary, practical and software-oriented learning resources. Usually, each math-block had an associated file containing computer data or computer laboratories with step-by-step guidance. Additionally, online homework and tests were included at different times during the semester. In the mathematical courses, these tests and homework were especially designed to promote the use of mathematical software among students. 


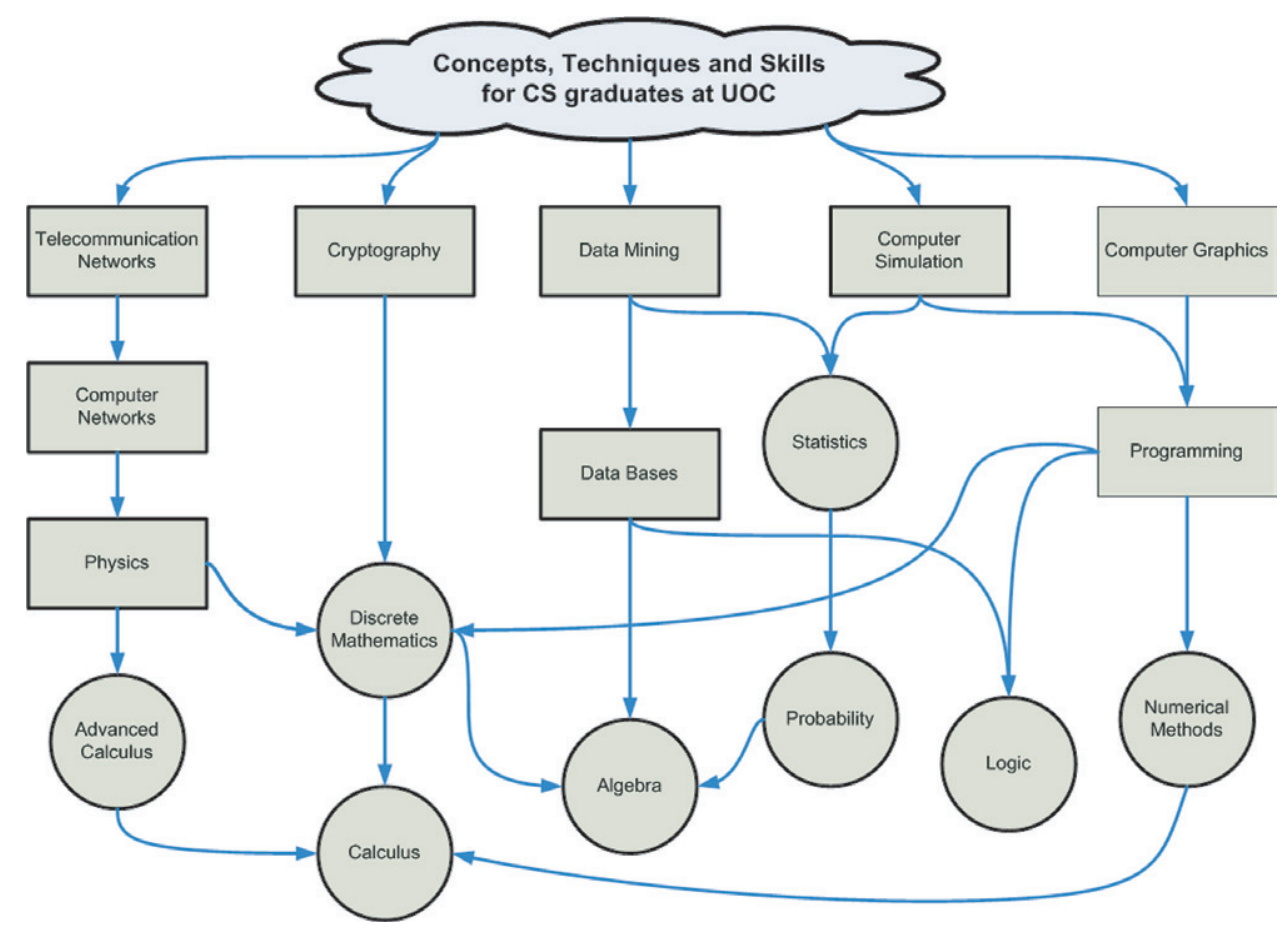

Figure 3. Using a top-down approach to redesign the CS curricula at the UOC.

\subsection{Stage 3 (2005-2007): curricula redefinition following a top-down approach}

During this third stage, education technology resources have been fully integrated into the mathematics courses. Special attention has been paid to the use of mathematical software and Java applets. They are used: (a) to perform real-life calculations that illustrate applications of mathematics to computer science problems, and (b) as interactive tools that help students to understand mathematical concepts by experimentation and visualization. Also, another major innovation has been developed at this stage: a complete redefinition of the Computer Science curricula. The CS faculty staff was grouped in interdisciplinary work teams, each of them composed of lecturers from different knowledge areas. Each of these teams worked for months in order to identify those concepts, techniques and skills that our graduating students should have. Recommendations from the Association for Computing Machinery (ACM, www.acm.org/education/curricula.html) were considered and different curricula from universities worldwide were analysed and discussed. Finally, members of each team got together to share results and extract conclusions regarding the educational needs of our students. Taking these educational needs as a starting point, all CS curricula were redefined using a top-down approach, i.e.: starting with the 'top subjects' - those located at the last semester in the CS curricula, and descending until the 'bottom ones' - those located at the first semester. The major dependencies among subjects were identified and a dependencies map of contents linking different subjects was established (Figure 3). According to this map, all subjects of the CS degree were redefined, both in contents - giving priority to those contents that students will need in other subjects or in their future professional activity - and in orientation - promoting a practical and updated approach to all subjects instead of a more theoretical and traditional one. 
Table 2. Hypothesis tests on the differences of two proportions $\left(\mathrm{p}_{2007}-\mathrm{p}_{2004}\right)$.

\begin{tabular}{lccrr}
\hline Question & $\begin{array}{c}2004 \\
(n=80)\end{array}$ & $\begin{array}{c}2007 \\
(n=100)\end{array}$ & $Z$ & $p$-value \\
\hline 1. Contents of the course are useful & $38 \%$ & $56 \%$ & 2.52 & 0.012 \\
2. Course workload corresponds to assigned credits & $48 \%$ & $61 \%$ & 1.82 & 0.069 \\
3. Learning materials are satisfactory & $54 \%$ & $71 \%$ & 2.40 & 0.016 \\
4. Mathematical software is helpful & $51 \%$ & $87 \%$ & 5.48 & 0.000 \\
5. Global evaluation of the course is positive & $48 \%$ & $70 \%$ & 3.12 & 0.002 \\
\hline
\end{tabular}

Our goal was to redesign all subjects taking into consideration a global vision of the CS curricula instead of a more fractional vision restricted to each individual subject.

\section{Testing effects of methodological changes at the UOC}

In order to test whether or not methodological changes introduced by the UOC faculty had any effect on students' perceptions of mathematics courses, we decided to perform the following analysis: A random sample of size 80 was drawn from the population of learners who had completed the continual evaluation process in any mathematics course during the academic year 2003/04. Two weeks before the final exams, the selected students were asked to individually answer the following simple questionnaire:

1. Do you think that the course contents are useful?

2. Does the course workload correspond to the assigned credits?

3. Are the learning materials satisfactory?

4. Have you found mathematical software helpful?

5. Is your global evaluation of the course positive?

Three years later, during the academic year 2006/07, another random sample of size 100 was drawn in similar conditions and, again, the selected students were asked to answer the same basic questionnaire. Note that at this moment we had two sets of proportions, each of them associated to a different stage - as described in the previous section. For each question $i(i=1,2, \ldots, 5)$, we consider the corresponding hypothesis test on the differences between the two population proportions [37], i.e.: $H_{0}: p_{2007}^{i}-p_{2004}^{i}=0$ versus $H_{0}: p_{2007}^{i}-p_{2004}^{i} \neq 0$. Results for these tests are shown in Table 2.

Using a standard significance level, $\alpha=0.05$, we can conclude from the corresponding p-values that tests associated with questions 1, 3, 4 and 5 are significant. In other words, statistical evidence supports the idea that methodological changes introduced at the beginning of stage 3 have contributed to significantly enhance students' perceptions regarding mathematics courses.

\section{Future perspectives on e-learning and mathematical e-learning}

E-learning is a rapidly growing activity, and more and more students are getting their education through web-based courses. Around the world, new institutions are emerging to offer Internet-based education. Just in Spain, for instance, two new Internet-based universities will be offering online education quite soon: the Valencian International 
University (VIU) and the Distance University of Madrid (UDIMA). At the same time, most face-to-face universities are integrating e-learning technologies and methodologies in their academic programs [38].

Regarding mathematical e-learning education, Miner and Topping [34] forecast the following trends: (a) a continuing move away from static mathematics to dynamic mathematics - use of MathML and OpenMath standards - in distance learning materials, and (b) an integration of e-learning technologies in face-to-face mathematical education as a way to complement and reinforce traditional methodologies. Similar statements can be found in [39]. In our opinion, this convergence between e-learning models and face-to-face educational models is an important fact that will significantly change the way mathematical education is delivered at universities. In this sense, during the next years we expect a significant increase in the number of joint mathematics programs and courses. Furthermore, we also expect the development of a large number of online collaborative mathematical projects, especially those related to the elaboration of open materials and resources for teaching and learning mathematics, including online assessment technologies. Other important trends that we foresee are: a higher integration of mathematical software in all courses - especially those following a student-centred methodology -, and the adoption of a more professionally oriented approach in most mathematics courses - both in face-to-face and online education. As Bringslid [35] points out: 'The overall profit of using interactive mathematics on the Web will be to stimulate interest in mathematics.'

\section{Concluding remarks}

Teaching and learning mathematics at the Open University of Catalonia has required an especial effort both from faculty and students. This effort has been mainly oriented to overcome several methodological difficulties, which are basically due to the fact that traditional face-to-face education models can not be directly implemented into an e-learning environment. In a pure Interned-based education, students and instructors do not have a face-to-face relationship and, in most cases, they do not even have a synchronous communication. Therefore, innovation is necessary, both in the use of technology as in the application of new methodological approaches. As a direct consequence of this innovation process, we have constructed and implemented a practical model to design and develop MEL courses at the UOC. This model is supported by the following pillars: (a) use of a top-down approach when redesigning mathematics courses in the global context of a degree program curricula; (b) use of a professionally oriented approach during the development of mathematics courses - i.e.: focusing on mathematical applications instead of on mathematical abstract theory; (c) integration of mathematical software throughout the courses to highlight real applications of mathematical concepts, methods and results; (d) development of electronic and interactive materials that facilitate upgrading and learning by experimentation; (e) prior evaluation of students' background in order to provide them with the appropriate assistance and resources from the beginning; (f) use of continual evaluation models that guide and prepare students for the final face-to-face exam; and (g) promotion of online collaborative learning among students via the assignment of small projects and group activities. According to experimental data, it seems that these innovations have both increased our students' interest for mathematics and enhanced their global evaluation of these courses. 


\section{Acknowledgments}

This work has been partially supported by the Spanish Ministry of Education under grant EA2007-0310. We would also like to gratefully acknowledge the support received from the CIMANET research group and from the REMIC research network.

\section{Notes}

1. In this article, we refer to 'mathematics' in a general sense, i.e.: the term also includes disciplines such as statistics, operations research, etc.

2. This article includes some words that are or are asserted to be proprietary terms or trade marks. Their inclusion does not imply they have acquired for legal purposes a non-proprietary or general significance, nor is any other judgement implied concerning their legal status.

\section{References}

[1] A. Bates, Technology, E-Learning and Distance Education, RoutledgeFalmer, Abingdon, 2005.

[2] S. Seufert, U. Lechner, and K. Stanoevska, A reference model for online learning communities, Int. J. E-Learn. 1 (2002), pp. 43-54.

[3] J. Engelbrecht and A. Harding, Teaching undergraduate mathematics on the Internet. Part 1: Technologies and taxonomy, Educ. Stud. Math. 58 (2005), pp. 235-252.

[4] C. Raschke, The Digital Revolution and the coming of the Postmodern University, RoutledgeFalmer, London, 2003.

[5] M. Borba and M. Villarreal, Humans-with-Media and the Reorganization of Mathematical Thinking, Springer, New York, 2005.

[6] K. Lai, K. Pratt, and A. Grant, State of the Art and Trends in Distance, Flexible, and Open Learning: A Review of the Literature (2003). Available at www.otago.ac.nz/courses/distance study/pdf/distance_lit_review.pdf

[7] C. Zirkle, Distance education in career and technical education: A review of the research literature, J. Vocat. Educ. Res. 28 (2003), pp. 151-171.

[8] G. Rodríguez, and A. Villa, Can computers change the trends in Mathematics Learning?: A Spanish overview. Plenary lecture at the 4th International Conference APLIMAT (2005). Available at: dmath.hibu.no/Rodrigez-De_la_VillaAplimath.pdf

[9] B. Barton et al. EAL undergraduates learning mathematics, Int. J. Sci. Math. Edu. 7 (2005), pp. 721-729.

[10] Qualitiy Assurance Agency for Higher Education (QAA), Code of Practice for the assurance of academic quality and standards in higher education, United Kingdom, 2006. Available at http://www.qaa.ac.uk/academicinfrastructure/codeOfPractice/

[11] S. Michael and L. Balraj, Higher education institutional collaborations: an analysis of models of joint degree programs, J. High. Edu. Pol. Manage. 25 (2003), pp. 131-145.

[12] A. Sikora and C. Carroll, A Profile of Participation in Distance Education: 1999-2000, National Center for Education Statistics, U.S. Department of Education, Washington, DC, 2002.

[13] R. Wagner, J. Werner, and R. Schramm, An Evaluation of Student Satisfaction in Distance Learning Courses, in Proceedings of the 18th Annual Conference on Distance Teaching and Learning, USA. University of Wisconsin System, Madison, 2002.

[14] C. Willis and R. Joyner, Perceptions of an On-campus/Online and a Off-campus/ Online Information Processing Course, in Proceedings of the 17th Annual Meeting of the Atlantic Coast Business and Marketing Education Conference, Raleigh, North Carolina, February, 2000, 18-19. 
[15] C. McCullough and V. Aimard, E-Learning in Europe: How do trainers, teachers and learners rate e-learning? (2006). Available at http://elearningeuropa.info

[16] R. Sweet, Student drop-out in distance education: an application of Tinto's model, Distance Edu. 7 (1986), pp. 201-213.

[17] M. Simonson et al. Teaching and Learning at a Distance, Merrill Prentice Hall, Upper Saddle River, NJ, 2003.

[18] K. Meyer, Quality in distance education. Focus on Online learning, Jossey-Bass, Hoboken, 2002.

[19] P. Petocz et al., Undergraduate students' conceptions of Mathematics: an international study, Int. J. Sci. Math. Edu. 5 (2007), pp. 439-459.

[20] G. Oates et al., Effective tutorial programmes in tertiary mathematics, Int. J. Sci. Math. Edu. 7 (2005), pp. 731-739.

[21] B. Birnbaum, Foundations and Practices in the Use of Distance Education, Edwin Mellen Press, Lewiston, NY, 2001.

[22] R. Newton, Staff attitudes to the development and delivery of e-learning, New library world 104 (2003), pp. 412-425.

[23] K. Pajo and C. Wallace, Barriers to uptake of web based technology by university teachers, J. Dist. Edu. 16 (2001), pp. 70-84.

[24] B. Yushau, Computer attitude, use, experience software familiarity and perceived pedagogical usefulness: the case of mathematics professors, Eur. J. Math., Sci. Techno. Edu. 2 (2006), pp. $1-17$.

[25] A. Trindade, H. Carmo, and J. Bidarra, Current developments and best practice in open and distance learning. International Review of Research in Open and Distance Learning, 1 (2000). E-journal. Available at: http://www.irrodl.org/index.php/irrodl/index

[26] Sloan Consortium, Growing by Degrees: Online Education in the United States, 2005. Available at: http://www.sloan-c.org/publications/survey/index.asp

[27] M. Hannafin, J. Hill, and M. Susan, Student-centered learning and interactive multimedia: status, issues, and implications, Contemp. Edu 68 (1997), pp. 94-97.

[28] J. Walczyk and L. Ramsey, Use of learner-centered instruction in college science and Mathematics classrooms, J. Res. Sci. Teach 40 (2003), pp. 566-584.

[29] J. Walczyk, L. Ramsey, and P. Zha, Obstacles to instructional innovation according to college science and mathematics faculty, J. Res. Sci. Teach. 44 (2007), pp. 85-106.

[30] L. Sakshaug, Research on distance education: implications for learning mathematics, Focus on Learn. Prob. Math. 22 (2000), pp. 111-124.

[31] S. Trenholm, A review of cheating in fully asynchronous online courses: a math or fact-based course perspective, J. Educ. Techno. Sys. 35 (2007), pp. 281-300.

[32] C. Corcoles et al., Math online education: state of the art, experiences and challenges. In Proceedings of the International Congress of Mathematicians, Madrid, Spain, August 22-30, 2006, pp. 578-579.

[33] Y. Lee, Integrating Constructivism approaches in e-learning to enhance mathematical selfstudy, in Proceedings of the Eighth International Conference on Reform, Revolution and Paradigm Shifts in Mathematics Education, Johor Bahru, Malaysia, Nov 25-Dec 1, 2005, pp. 238-243.

[34] R. Miner and P. Topping, Math on the Web: A Status Report - Focus: Distance Learning, 2001. Available at: http://www.dessci.com/en/reference/webmath/status

[35] O. Bringslid, Mathematical e-learning using interactive mathematics on the Web, Eur. J. Eng. Edu. 27 (2002), pp. 249-255.

[36] T. Daradoumis, F. Xhafa, and A. Juan, A framework for assessing self, peer and group performance in e-learning, Self, Peer, and Group Assessment in E-Learning, Idea Group Press, Hershey, PA, 2006, pp. 279-294.

[37] D. Montgomery and G. Runger, Applied Statistics and Probability for Engineers, John Wiley \& Sons, New York, 2004. 
[38] C. Richards, Distance education, on-campus learning, and e-learning convergences: an Australian exploration, Inter. J. E-Learning 1 (2002), pp. 30-39.

[39] J. Engelbrecht and A. Harding, Teaching undergraduate mathematics on the Internet. Part 2: attributes and Possibilities, Edu. Stud. Math. 58 (2005b), pp. 253-276.

\section{Appendix 1: Sample list of universities offering MEL}

A sample list of universities offering mathematical e-learning:

- Colorado State University (www.stat.colostate.edu/distance_degree.html)

- Iowa State Univ. of Science and Tech. (www.lifelearner.iastate.edu/courses/delivery/ www.htm)

- Stanford University (math.stanford.edu/)

- State University of New York Empire State College (www.esc.edu/cdl)

- Texas A\&M University (distance-ed.math.tamu.edu/)

- University of Idaho (www.uidaho.edu/eo/index.html)

- University of Illinois Online (www.online.uillinois.edu/)

- Suffolk University (distancecalculus.com/)

- Florida State University (online.fsu.edu/)

- University of Guelph (www.open.uoguelph.ca/start/)

- Open University (www3.open.ac.uk/courses/classifications/mathematics_and_statistics. shtm)

\section{Appendix 2: Relevant MEL projects}

A list of relevant technological projects related to mathematical e-learning:

- NetTutor and Whiteboard (www.link-systems.com): NetTutor is a web-based graphical chat. WorldWideWhiteboard is an interactive graphical chat tool designed to allow realtime communication of technical concepts, including support for mathematical notation.

- PlanetMath (planetmath.org): It is a virtual community which aims to help make mathematical knowledge more accessible.

- WIMS (wims.unice.fr): It is a purpose written system that has pages for mathematical problems and a graphing facility.

- Maths for More (www.mathsformore.com): It is a mathematical software company which is responsible for WIRIS, a software suite of tools for mathematics education.

- ActiveMath (www.activemath.org): Its goal is world-class research on technologyenhanced learning and instruction and on Semantic Web technology.

- The Math Forum (mathforum.org): It is an online resource for improving mathematical learning, teaching and communication that offers mathematical problems and puzzles, online mentoring, research, team problem solving, collaboration and professional development.

- Mathworld (mathworld.wolfram.com): It is an extensive web-based mathematical resource, provided as a free service.

- dMath (dmath.hibu.no): This project is building a European database of mathematical e-learning modules. These modules can be used in web-based courses in mathematics. The project is a commercialization of former project Xmath.

- WebALT (http://www.webalt.net/): This project aims at using existing standards for representing mathematics on the web and existing linguistic technologies to produce language-independent mathematical didactical material.

- MIT OpenCourseware (ocw.mit.edu/index.html): It is a free and open educational resource for educators, students and self-learners around the world.

- HELM (helm.lboro.ac.uk): It is a major curriculum development project undertaken by a consortium of five English universities.

- Serving Mathematics (mantis.york.ac.uk): This project has been developing open-source tools for online assessment in mathematics education. 


\section{Appendix 3. Relevant MEL technologies and standards}

A list of advanced technologies and standards related to mathematical e-learning:

- WebMathematica (www.wolfram.com/products/webmathematica): It is a web-based technology that allows the generation of dynamic web content with Mathematica. It allows distance students to explore and experiment with some of the mathematical concepts by means of their web browser.

- Maple TA (www.maplesoft.com/products/mapleta): Maple T.A. is a web-based testing and assessment system that supports complex, free-form entry and intelligent evaluation of responses.

- MathML (www.w3.org/math): It is an application of XML for representing mathematical symbols and formulae, aimed at integrating them into web documents.

- OpenMath (www.openmath.org): It is an emerging standard for representing mathematical objects with their semantics, allowing them to be exchanged between computer programs, stored in databases, or published on the worldwide web.

- WebCT (www.webct.com): It is an online commercial virtual learning environment system.

- Blackboard (www.blackboard.com): It offers similar functionalities to those of WebCT. In February 2006, Blackboard Inc. completed a merger with WebCT Inc.

- Moodle (www.moodle.com): It is a free software package designed to help educators create quality online courses by the development of a virtual learning environment.

- Angel (www.angellearning.com): It is a web-based course management system similar to WebCT, Moodle or Blackboard. 